\title{
Avaliação de mudas de beterraba em função do substrato e do tipo de bandeja
}

\section{Evaluation of substrate and tray types for beet seedlings}

\author{
Márcia de Moraes Echerr'; Vandeir Francisco Guimarães ${ }^{2 *}$; Alice Noemi Aranda \\ Erreinaldo Donizete Bortolazzo ${ }^{3}$; Juliana Souza Braga ${ }^{3}$.
}

\section{Resumo}

\begin{abstract}
Visando avaliar o efeito de três substratos, Plantimax, Mogimax, Gioplanta, e bandejas de poliestireno expandido com 128 e 200 células, na produção de mudas de beterraba da cultivar "Early Wonder", realizou-se um experimento no período de abril a maio de 1998 em Piracicaba- SP. A avaliação foi realizada 40 dias após a semeadura e as variáveis estudas foram altura da planta, comprimento do sistema radicular, massa seca total, massa seca da parte aérea, massa seca de raiz e determinada a razão entre a massa seca da parte aérea e a massa seca das raízes (RPAR). O delineamento experimental utilizado foi de blocos casualizados, em esquema fatorial 3 x 2, com 4 repetições. Em todas as variáveis estudas foi observada diferença significativa para substratos e recipientes. Para massa seca da parte aérea, massa seca total e RPAR foram observadas interações significativas entre tipo de substrato e bandeja. Plantimax e Mogimax mostraram-se superiores para maioria dos parâmetros avaliados. A bandeja com 128 células proporcionou a produção de mudas de melhor qualidade, com maior acúmulo de massa seca, quando comparada às mudas produzidas em bandejas de 200 células, sendo a mais indicada para produção de mudas de beterraba.
\end{abstract}

Palavras-chave: Beta vulgaris, produção de mudas, massa seca

\begin{abstract}
The experiment was carried out from April to May of 1998 in Piracicaba- SP, with the objective of evaluating three substrates: Plantimax, Mogimax and Gioplanta, and two recipient trays: one with 128 cells and other with 200 cells, in beet seedling production of cultivar "Early Wonder". The evaluation was accomplished 40 days after sowing by the following parameters: plant height, root length, total dry mass, root dry mass, shoot dry mass and the shoot/root relation. The experimental design was randomized blocks in $3 \times 2$ outline factorial with 4 replications. In all evaluated parameters, there were found significant differences among substrates and trays. Also, it was observed significant interaction in total dry mass, shoot dry mass and shoot/root relation. Plantmax and Mogimax were superior for the most of the evaluated parameters. Recipient tray with 128 cells was better than 200 cells, being more indicated for beet seedling production.

Key words: Beta vulgaris, seedling production, dry matter
\end{abstract}

1 Eng. Agrônoma, Doutora em Fitotecnia.

2 Prof. Adjunto do Centro de Ciências Agrárias,UNIOESTE-Marechal Cândido Rondon-PR. E-mail: vandeirfg@yahoo.com.br.

3 Eng. Agrônomo.

* Autor para correspondência 


\section{Introdução}

A produção de mudas de hortaliças constitui-se em umas das etapas mais importantes do sistema produtivo, influenciando diretamente o desempenho final das plantas. Uma muda má formada debilita e compromete todo o desenvolvimento da cultura, aumentando seu ciclo e levando a perdas na produção.

Tradicionalmente, a cultura da beterraba (Beta vulgaris L.) tem sido estabelecida por semeadura direta, por transplante de mudas produzidas em bandejas ou pelo transplante de mudas de raiz nua. No entanto, estes métodos proporcionam estandes desuniformes em função da germinação ou do estresse causado pelo transplante. As mudas formadas em sementeiras são transplantadas com raiz nua, sem torrões ao seu redor, sendo muito sensíveis às condições ambientais, além de provocar danos no sistema radicular e serem contaminadas por patógenos (SOUZA; FERREIRA, 1997). Além disso, contrariamente ao que ocorre com outras hortaliças tuberosas, a beterraba adapta-se bem ao transplante (FILGUEIRA, 2003). Assim, uma alternativa é a produção de mudas de beterraba em bandejas, devido às vantagens que o método proporciona. Segundo Mattos (1995) a produção de mudas em viveiros propicia a utilização de substratos de germinação livres de patógenos, um melhor aproveitamento do material propagativo e seleção de mudas de melhor qualidade para transplante.

Silva e Vizzotto (1993) relataram que o desconhecimento de tecnologia de produção de mudas tem levado o olericultor a utilizar diferentes práticas culturais, muitas vezes inadequadas, que refletem diretamente na baixa produtividade e qualidade das raízes.

Apesar do transplante de mudas prolongar o ciclo da cultura, esta prática eleva a produtividade e a qualidade do produto, além de reduzir a quantidade de semente gasta (FILGUEIRA, 2003). A produção de mudas apresenta-se como uma alternativa para determinadas espécies ou variedades que apresentam problemas e necessitam de um maior cuidado na fase de germinação e emergência da plântula.

Segundo Oliveira, Scivittaro e Vasconcellos (1993), o uso de recipientes como bandeja de poliestireno expandido tem se mostrado eficiente em sistema de produção de mudas sob vários aspectos, tais como economia de substrato e de espaço dentro casa-de-vegetação, menor gastos com produtos fitossanitários, produção de mudas com alta qualidade e elevado índice de pegamento após o transplante.

Na produção de um muda de alta qualidade devese considerar o tamanho do recipiente e o tipo de substrato a ser utilizado, pois estes fatores afetam diretamente o desenvolvimento e a arquitetura do sistema radicular (LATIMER,1991), bem como o fornecimento de nutrientes (CARNEIRO, 1983). Na literatura são relatados vários estudos que demonstram o efeito do volume do recipiente no desenvolvimento de mudas de alface (SILVA et al., 2000a), brócolos (SILVA et al., 2000b), pimentão (BARNABÉ; GIORGETTI; GOTO, 1994), tomate e pepino (BARROS, 1997).

Neste contexto, o presente trabalho teve como objetivo avaliar o efeito de três substratos e de dois tamanhos de células para a produção de mudas de beterraba em bandejas de poliestireno expandido.

\section{Material e Métodos}

O experimento foi conduzido na área experimental do setor de Horticultura, do Departamento de Produção Vegetal da Escola Superior de Agricultura "Luiz de Queiroz" (ESALQ) em Piracicaba-SP, no período de abril a maio de 1998. Utilizou-se a cultivar de beterraba "Early Wonder" e os tratamentos consistiram da combinação de três substratos comerciais: Plantimax, Mogimax e Gioplanta, em dois tamanhos de badejas piramidal de poliestireno expandido, com 128 e 200 células, com volume de 32 e $16 \mathrm{~cm}^{3}$, respectivamente. O delineamento estatístico utilizado foi de blocos casualizados, em esquema fatorial 3 x 2, com 4 repetições. 
Na semeadura foram distribuídos três glomérulos por célula. Uma semana após a germinação efetuouse o desbaste, deixando uma planta por célula. Aos 27 dias após a semeadura realizou-se adubação foliar para todos os tratamentos na dosagem de $1 \mathrm{~g} \mathrm{~L}^{-1} \mathrm{de}$ fertilizantes com a concentração: NPK (4-16-8), B $(0,70 \%)$. As bandejas foram mantidas sob condições de casa-de-vegetação e a irrigação foi realizada por um sistema intermitente com microaspersão, sendo os intervalos de irrigação controlados conforme as condições ambientais prevalecentes.

Aos 40 dias após a semeadura realizou-se a avaliação do experimento, retirando-se 20 plantas por parcela. Após a coleta, as plantas foram levadas ao laboratório onde determinou-se a altura de plantas $(\mathrm{cm})$, medida do colo até o ápice da planta $(\mathrm{H})$ com auxílio de uma régua. Posteriormente as plantas foram seccionadas separando-se a parte aérea do sistema radicular. As raízes foram lavadas para remover o substrato, sendo determinado, em seguida, o comprimento das raízes (CR) com régua. As diferentes partes das plantas foram acondicionadas em sacos de papel e secas em estufas de circulação forçada de ar a $65^{\circ} \mathrm{C} \pm 5^{\circ} \mathrm{C}$, até atingirem massa constante. Determinou-se, com uma balança de precisão, a massa seca da parte aérea (MSPA) e a massa seca das raízes (MSR). Calculou-se então a massa seca total (MST) e a razão entre a massa seca da parte aérea e a massa seca das raízes (RPAR).

Após tabulados, os dados foram submetidos à análise de variância, e as médias comparadas pelo teste de Tukey a 5\% de probabilidade.

\section{Resultados e Discussão}

Os resultados relativos ao efeito de substratos e recipientes e a interação entre ambos, na produção de mudas de beterraba da cultivar "Early Wonder", para os diferentes parâmetros testados, são mostrados nas Tabelas 1, 2 e 3.

Pela análise de variância é possível verificar que houve diferença significativa para os fatores substrato e tamanho de célula utilizado, pelo teste $\mathrm{F}$, em relação aos parâmetros avaliados. Quanto à interação entre os fatores, esta foi significativa somente para as variáveis massa seca da parte aérea (MSPA), massa seca total (MST) e razão parte aérea/ raiz (RPAR) (Tabela 1).

Tabela 1. Análise de variância da altura da planta $(\mathrm{H})$, comprimento do sistema radicular $(\mathrm{CR})$, massa seca da parte aérea (MSPA), massa seca de raízes (MSR), massa seca total (MST) e razão entre a massa seca da parte aérea e a massa seca das raízes (RPAR), de mudas de beterraba, cultivar "Early Wonder", produzidas em três substratos e dois recipientes. Piracicaba, 1998.

\begin{tabular}{lccccccc}
\hline \multicolumn{7}{c}{ QUADRADO MÉDIO DO RESÍSDUO } \\
\hline F. de Variação & GL & H & CR & MSPA & MSR & MST & RPAR \\
\hline Bloco & 3 & $0,346^{\mathrm{ns}}$ & $0,310^{\text {ns }}$ & $0,0003^{\mathrm{ns}}$ & $0,0009^{*}$ & $0,0007^{*}$ & $0,161^{\mathrm{ns}}$ \\
Substrato (S) & 2 & $11,919^{* *}$ & $0,978^{* *}$ & $0,0040^{* *}$ & $0,0002^{* *}$ & $0,0060^{* *}$ & $0,577^{\mathrm{ns}}$ \\
Bandeja (B) & 1 & $23,069^{* *}$ & $16,550^{* *}$ & $0,0326^{* *}$ & $0,0028^{* *}$ & $0,0545^{* *}$ & $0,740^{\mathrm{ns}}$ \\
Interação (SxB) & 2 & $0,262^{\mathrm{ns}}$ & $0,297^{\mathrm{ns}}$ & $0,0009^{* *}$ & $0,0005^{\mathrm{ns}}$ & $0,0010^{* *}$ & $0,707^{*}$ \\
\hline Resíduo & 15 & 0,110 & 0,172 & 0,0001 & 0,00002 & 0,0001 & 0,201 \\
\hline
\end{tabular}

${ }^{\mathrm{n}}$ Não significativo $(\mathrm{F}<0,05)$; *Significativo $(\mathrm{F}<0,05)$; **Significativo $(\mathrm{F}<0,01)$. 
De acordo com os dados apresentados na Tabela 2, observou-se que a utilização dos substratos Plantimax e Mogimax resultou em mudas com maior massa seca de raízes (MSR) e altura $(\mathrm{H})$, quando comparada às mudas produzidas com o substrato Gioplanta, não havendo diferença significativa entre os dois primeiros substratos. Em trabalho realizado por Oliveira, Scivittaro e Vasconcellos (1993), usando diferentes substratos em bandejas de 72 e 128 células para formação de mudas de maracujá, estes observaram também que o substrato Plantimax foi o que se destacou quanto a MSR. Estes resultados são de grande importância, conforme mencionado por Minami (1995), que relata que quanto maior a quantidade de raízes, maior a quantidade de nutrientes disponíveis no intervalo entre o transplante e a formação de novas raízes. Filgueira (2003) afirma que um bom enraizamento e o reinício do desenvolvimento da planta, após o choque do processo de transplante são favorecidos por tecidos ricos em matéria seca. Para comprimento de raízes (CR), o substrato Gioplanta promoveu um maior crescimento quando comparado com os outros substratos.

Tabela 2. Altura da planta (H), comprimento do sistema radicular (CR) e massa seca de raiz (MSR), de mudas de beterraba, cultivar "Early Wonder", produzidas em três substratos e dois recipientes. Piracicaba, 1998.

\begin{tabular}{lccc}
\hline Substrato & H $(\mathbf{c m})$ & CR $(\mathbf{c m})$ & MSR (g) \\
\hline Plantimax & $9,05 \mathrm{~A}$ & $8,69 \mathrm{~B}$ & $0,04 \mathrm{~A}^{1}$ \\
Mogimax & $9,01 \mathrm{~A}$ & $8,99 \mathrm{~B}$ & $0,04 \mathrm{~A}$ \\
Gioplanta & $6,91 \mathrm{~B}$ & $9,69 \mathrm{~A}$ & $0,03 \mathrm{~B}$ \\
\hline Bandeja & $\mathbf{H}(\mathbf{c m})$ & $\mathbf{C R}(\mathbf{c m})$ & MSR (g) \\
\hline 128 Células & $9,30 \mathrm{a}$ & $9,85 \mathrm{a}$ & $0,05 \mathrm{a}^{2}$ \\
200 Células & $7,34 \mathrm{~b}$ & $8,19 \mathrm{~b}$ & $0,03 \mathrm{~b}$ \\
\hline $\mathbf{C V}(\%)$ & 3,98 & 4,59 & 13,15 \\
\hline
\end{tabular}

${ }^{1}$ Médias seguidas pela mesma letra, maiúscula para comparação entre substratos e ${ }^{2}$ minúscula para a comparação entre bandejas, não diferem estatisticamente entre si pelo teste de Tukey $(\mathrm{P}<0,05)$.

Ainda na Tabela 2, na comparação entre as bandejas, observou-se que a de maior volume de substrato (128 células) apresentou desempenho superior para as variáveis massa seca de raízes, altura de planta e comprimento do sistema radicular, provavelmente, devido à maior disponibilidade de fatores de crescimento, como: nutrientes, água, espaço físico e luminosidade. De maneira geral, podese observar que bandejas com células de maior volume de substrato a ser explorado propiciaram melhor desenvolvimento da muda.

Souza e Ferreira (1997) relatam que a produção de mudas de hortaliças constitui-se em umas das etapas mais importantes do sistema produtivo, influenciando diretamente o desempenho final das plantas. Mudas que apresentam alguma restrição no desenvolvimento do sistema radicular, ao serem transplantadas para o campo, têm dificuldade de compensar a evapotranspiração, mesmo se bem irrigadas após o transplante (WIEN, 1997). Neste sentido, apesar do maior gasto com substrato, em função de um maior volume de células, a formação da muda deve ser considerada, visando o sucesso após o transplante, que pode resultar em maior produtividade.

$\mathrm{Na}$ Tabela 3 são apresentados os efeitos da interação entre tamanho das células das bandejas e o tipo de substrato para as variáveis MSPA, MST e RPAR. Observa-se que a utilização de Mogimax resultou em mudas com maior MSPA e MST, diferindo dos substratos Plantimax e Gioplanta para Bandeja de 128 células. Para RPAR, não ocorreram diferenças entre substratos, nesta bandeja. 
Tabela 3. Massa seca da parte aérea (MSPA), massa seca total (MST) e razão entre a massa seca da parte aérea e a massa seca das raízes (RPAR), de mudas de beterraba, cultivar "Early Wonder", produzidas em três substratos e dois recipientes. Piracicaba, 1998.

\begin{tabular}{|c|c|c|c|c|c|c|}
\hline \multirow{3}{*}{ Substrato } & \multicolumn{2}{|c|}{ MSPA (g) } & \multicolumn{2}{|c|}{ MST (g) } & \multicolumn{2}{|c|}{ RPAR } \\
\hline & \multicolumn{6}{|c|}{ Bandeja } \\
\hline & 128 células & 200 células & 128 células & 200 células & 128 células & 200 células \\
\hline Plantimax & $0,14 \mathrm{bA}^{1}$ & $0,08 \mathrm{aB}$ & $0,19 \mathrm{bA}$ & $0,11 \mathrm{aB}$ & $2,57 \mathrm{aA}$ & $2,90 \mathrm{aA}$ \\
\hline Mogimax & $0,17 \mathrm{aA}$ & $0,07 \mathrm{aB}$ & $0,22 \mathrm{aA}$ & $0,10 \mathrm{aB}$ & $3,34 \mathrm{aA}$ & $2,65 \mathrm{abB}$ \\
\hline Gioplanta & $0,11 \mathrm{cA}$ & $0,04 \mathrm{bB}$ & $0,15 \mathrm{cA}$ & $0,07 \mathrm{bB}$ & $2,81 \mathrm{aA}$ & $2,10 \mathrm{bB}$ \\
\hline CV (\%) & \multicolumn{2}{|c|}{10,45} & \multicolumn{2}{|c|}{8,72} & \multicolumn{2}{|c|}{16,44} \\
\hline
\end{tabular}

${ }^{1}$ Médias seguidas pela mesma letra, minúscula nas colunas e maiúscula nas linhas, não diferem estatisticamente entre si pelo teste de Tukey $(\mathrm{P}<0,05)$.

Com relação ao volume do recipiente, a bandeja de 128 células diferiu estatisticamente da bandeja de 200 células, sendo superior para todas as variáveis avaliadas (Tabela 3), confirmando os resultados apresentados na Tabela 2. Barros (1997) obteve resultado semelhante estudando a produção de mudas de pepino e tomate. Este fato provavelmente se deve ao maior volume de substrato que está envolvendo a planta neste tipo de bandeja, propiciando condições satisfatórias ao seu desenvolvimento (OLIVEIRA; SCIVITTARO; VASCONCELLOS, 1993).

Os tipos e tamanhos de bandejas utilizadas para produção de mudas são muito variados. Observa-se que existe tendência ao uso de bandejas com células de menor volume, uma vez que, quanto menor o número de células, maior o número de mudas que podem ser obtidas por área de estufa, além da menor necessidade de substrato e, consequentemente, menor custo na produção de mudas (GODOY; CARDOSO, 2005). Contudo, a economia conseguida pode ser prejudicial à produção final, pois em células de menor volume o espaço físico e a quantidade de substrato pode ser insuficiente para o desenvolvimento do adequado das mudas, impedindo que as cultivares expressem seu potencial genético, reduzindo a produtividade e qualidade do produto final.
Salvador, Paqual e Spera (2001) relatam que em células de menor volume, em conseqüência da maior concentração de raízes, há maior demanda de oxigênio e de renovação de $\mathrm{CO}_{2}$. Além disso, a produção de mudas em células menores requerem irrigações mais freqüentes para suprimento da demanda de água, pois a quantidade de substrato pode não ser suficiente para retenção de água para manter a taxa de crescimento da muda. Contudo, irrigações muito freqüentes podem ocasionar a lixiviação de nutrientes, sendo necessária uma complementação mineral. Em contrapartida, podese levantar como desvantagem do uso de bandejas com células de maior volume, o maior gasto com substrato, aliado à menor produção de mudas por área de ambiente protegido.

Segundo Leskovar (1998), variando-se o tamanho do recipiente altera-se o volume de enraizamento das plantas, o qual afeta o crescimento da parte aérea, sendo observada uma relação positiva entre a massa seca do sistema radicular e da parte aérea. Verificase na Tabela 3 que existiu efeito tanto do substrato utilizado para a produção de mudas de beterraba como do tamanho das células da bandeja, para esta variável. Bandejas de 128 células proporcionaram maior desenvolvimento da parte aérea e das raízes 
das mudas de beterraba, além de resultar em mudas com maior razão raiz parte aérea, característica importante quando se refere à qualidade da muda e rápido estabelecimento pós-transplante.

\section{Conclusão}

Com base nos resultados apresentados, pode-se concluir que o tamanho das células das bandejas e os substratos utilizados influenciaram na formação de mudas de beterraba, sendo que células de maior volume proporcionaram mudas maiores e de melhor qualidade.

\section{Referências}

BARNABÉ, F. A.; GIORGETTI, J. R.; GOTO, R. Influência de três tipos de bandejas para a produção de mudas de pimentão. Horticultura Brasileira, Brasília, v.18, p.71, 1994. Suplemento.

BARROS, S. B. M. Avaliação de recipientes na produção de mudas de tomate (Lycopersicon esculentum Mill.) e pepino (Cucumis sativus L.). 1997. (Dissertação de Mestrado) - Universidade de São Paulo. Piracicaba.

CARNEIRO, J. G. de A. Variações na metodologia de mudas florestais afetam os parâmetros morfo-fisiologicos que indicam a sua qualidade. Série Técnica FUPEP, Curitiba, v.12, p.1-40, 1983.

FILGUEIRA, F. A. R. Novo manual de olericultura: agrotecnologia moderna na produção e comercialização de hortaliças. 2.ed. Viçosa: UFV, 2003.

GODOY, M. C.; CARDOSO, A. I. I. Produtividade da couve-flor em função da idade de transplante das mudas produzidas e tamanhos de células na bandeja. Horticultura Brasileira, Brasília, v.23, n.3, p.837-840, 2005.
LATIMER, J. G. Container size and shape influence growth and landscape performance of marigold seedling. HortScience, Alexandria, v.26, n.2, p.124-126, 1991.

LESKOVAR, D.I. Root and shoot modification by irrigation. HortTechnology, Alexandria, v.8, p.510-514, 1998.

MATTOS, J.K.A. Doenças causadas por fungos em batata-doce, beterraba, cará, gengibre e inhame. Informe Agropecuário, Belo Horizonte, v.17, n.182, p.25-28, 1995.

MINAMI, K. Produção de mudas de alta qualidade em horticultura. São Paulo: T.A. Queiroz, 1995.

OLIVEIRA, R. P.; SCIVITTARO, W. B.; VASCONCELLOS, L. A. B. C. Avaliação de mudas de maracujazeiro em função do substrato e do tipo de bandeja. Scientia Agrícola, Piracicaba, v.50, n.2, p.261-266, 1993.

SALVADOR, E. D.; PAQUAL, M.; SPERA, M. R. N. Efeito de diferente substratos no crescimento de samambaiamatogrossensis (Polypodium aureum L.). Ciência Agrotécnica, Lavras, v.25, n.4, p.1006-1011, 2001.

SILVA, A. C. F. da; VIZZOTTO, V. J. Espaçamento e método de cultivo adequados aumentam a produtividade e a qualidade da beterraba. Agropecuária Catarinense, Florianópolis, v.6, n.1, p.14-16, 1993.

SILVA, A. C. R.; FERNANDES, H. S.; HOPPE, M.; MORAES, R. M. D.; PEREIRA, R. P.; JACOB-JÚNIOR, E. A. Produção de mudas de brócolis com vermicompostos em diferentes tipos de bandeja. Horticultura Brasileira, Brasília, v.18, p.514-515, 2000a. Suplemento.

SILVA, A. C. R.; FERNANDES, H. S.; MARTINS, S. R.; SILVA, J. B.; SCHIEDECK, G.; ARMAS, E. Produção de mudas de alface com vermicompostos em diferentes tipos de bandeja. Horticultura Brasileira, Brasília, v.18, p.512513, 2000b. Suplemento.

SOUZA, R. J.; FERREIRA, A. A. Produção de mudas de hortaliças em bandejas: economia de sementes e defensivos. A Lavoura, Rio de Janeiro, n.623, p.19-21, 1997.

WIEN, H. C. The physiology of vegetable crops. Oxon: CABI Publishing, 1997. 